\title{
INFORMATION SUPPORT OF OPTIMAL CONTROL OF MODES OF ELECTRIC SYSTEMS WITH RENEWABLE ENERGY SOURCES
}

\author{
Volodymyr V. Kulyk', Iryna A. Bartetska', Olga A. Buslavets², Michalina Gryniewicz-Jaworska³ \\ 1 Department of Electrical Stations and Systems, Vinnytsia National Technical University, 95 Khmelnitskoye \\ Shose, Vinnytsia, 21021, Ukraine \\ 2 Department of Electric Power Complex of Ministry of Energy and Coal Industry, 30 Khreshchatyk St., Kyiv, \\ 01601, Ukraine \\ ${ }^{3}$ Lublin University of Technology, Department of Grid Network and Security, michalina.gryniewicz.jaworska@vp.pl
}

Received: 2017.07.13

Accepted: 2017.11.01

Published: 2017.12.05

\begin{abstract}
To provide necessary quality of electric energy and reliable supply and reduce environmental contamination as a result of energy units operation, renewable sources of energy (RSE), in particular solar electric stations (SES), wind electric stations (WES) and small hydropower stations (SHES) are intensively developed. The paper considers the conditions of optimality of renewable sources of energy (RSE) functioning in electric systems, controllability of which is limited by the impact of non-stable weather conditions. The influence of control system information support on the efficiency of RSE usage is shown.
\end{abstract}

Keywords: renewable sources of electric energy, electric systems , optimal control, information support

\section{INTRODUCTION}

Characteristic feature of modern electric grids is the growth of loads and more rigid requirements, regarding the reliability of energy supply and quality of electric energy. To provide necessary quality of electric energy and reliable supply and reduce environmental contamination as a result of energy units operation, renewable sources of energy (RSE), in particular solar electric stations (SES), wind electric stations (WES) and small hydropower stations (SHES) are intensively developed.

Development of RSE as distributed generation in electric grids is urgent for all countries. In the countries of EU, for instance, the possibility to increase the share of renewable sources of energy up to $20 \%$ by 2020 is considered.

Such an approach has a number of advantages, namely, the possibility to provide the required quality of electric energy and reliability of energy supply as a result of smaller volumes of main equipment modernization, prolongation of the term of electric grids reconstruction and additional possibilities to attract investors to solve problems, aimed at increase of electric networks efficiency. Besides, new possibilities of increasing technical economic indices of electric grids at the expense of correction of connection schemes and parameters of RSE depending on their type and capacity.

As a result of transition from centralized energy supply to combined supply, new problems emerge, one of them being optimal control of RSE within local electric systems (LES), in which distributive electric systems are gradually transformed with the development of RSE $[1,2,3,6,9]$. The aim is to achieve maximum technical economic effect as a result of implementation of RSE and, to increase the capacities of new alternative and renewable sources of energy. This effect can be achieved by means of matching in time the op- 
timization of the process of generation, transporting and consumption of energy. Modern SMART Grid information and communication technologies play an extremely important role, providing information service of energy supply of the consumers from centralized large electric stations and RSE, distributed in LES.

The given paper considers the requirements to information support of decentralized control of RSE in local electric energy systems, the paper presents the conditions of optimality and the structure of RSE optimal control on the example of small hydropower stations and their chains as controlled sources in the aggregate with wind electric stations, solar installations, controllability of which is considerably limited by the dependence of the generation on non-stable weather conditions.

\section{CHARACTERISTICS OF RENEWABLE SOURCES OF ELECTRIC ENERGY AS THE OBJECT OF CONTROL}

Renewable sources of electric energy are divided according to the degree of influence of random processes of natural environment and primary sources of power into $[2,5,7,8]$ :

- renewable sources with variable generation - use renewable resources, but their generation greatly depends on natural conditions (WES, SES);

- renewable sources with non-variable generation - use renewable resources, and, generation is constant during certain period of time (SHES, etc.).
- as the reserve of RSE non-renewable sources with non-variable generation can be used in LES -they use organic fuel but provide controllability of generation process. Steam -gas installations (SGI), gas-turbine installations (GTI), cogeneration installations (CGI) are referred to these sources.

Renewable sources of energy of rather small installed capacity are distributed in LES on certain territory. Places of RSE location are determined by natural conditions and, as a rule, do not coincide with the consumption of energy, generated by RSE. That is why, provision of generation optimality, distribution and consumption processes, taking into account characteristic features of RSE in real time, requires powerful communication facilities of decentralized control system. Only under these conditions it is possible to realize such approaches, regarding the formation of control impacts and control laws of separate sources of energy, taking into account specific features of their controllability and observability, which would provide maximum system effect.

To realize problems of automatic control of RSE normal modes in local electric systems the usage of control system with SMART GRID technologies is expedient. The efficiency of active-adaptive approach is increased as a result of division of RSE modes control function - centralized formation of control laws according to complete mathematic models of electric system and RSE and decentralized realization of these laws in local control systems and regulation of separate RSE and their groups using the local information (Fig. 1).

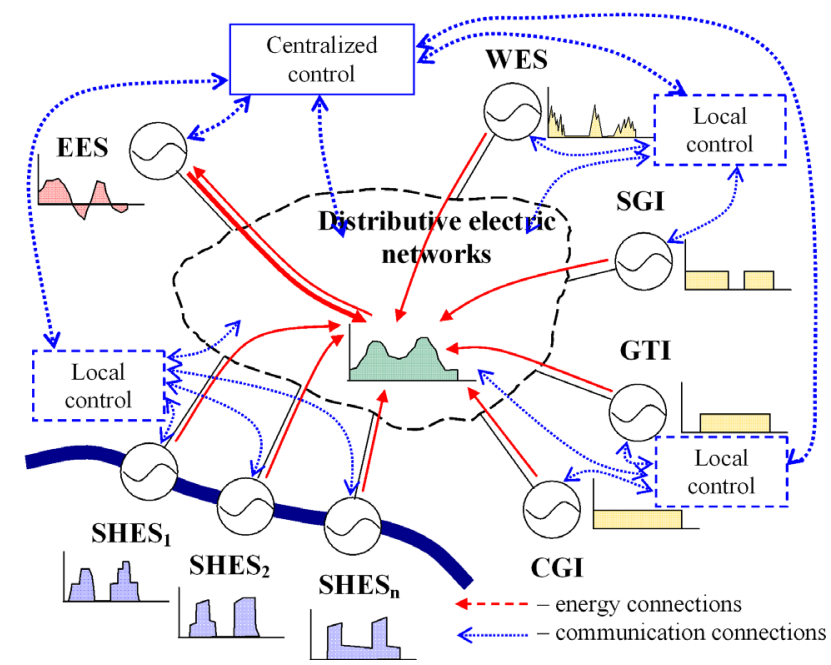

Fig. 1. Energy and communication connections of renewable sources of energy in SMART Grid 
In this case, the synthesis of control laws using limited information, is required, these laws would maximally represent the principles of centralized control. The realization of the given control concept enables to unload the centralized control level from computational operations, connected with determination of control impacts of separate RSE, and decreases the capacity of communication facilities, needed for centralized control.

\section{PROBLEM OF RSE OPTIMAL CONTROL IN LOCAL ELECTRIC SYSTEMS}

For optimization of RSE functioning in normal modes of electric systems the problems of planning organization and on-line control of operation mode of such stations in order to obtain maximum profit from their operation become very important. Hence, the most urgent, taking into account the specific features of profitability provision, is the task of optimization of daily modes (on time intervals $\left(t_{0} ; t_{k}\right)$ of controlled RSE $P_{i}(t), i=1.2 \ldots n$, taking into account modes of variable sources to provide maximum incomes from selling their electric energy on conditions of multistage tariff of energy market $\operatorname{tariff}(t)$ and technical limitations on the side of separate RSE.

$$
\begin{gathered}
\int_{t_{0}}^{t_{k}} \operatorname{tariff}(t) \sum_{i=1}^{n} P_{i}(t) d t \rightarrow \max \\
\left\{\begin{array}{l}
\int_{t_{0}}^{t_{k}} \operatorname{tariff}(t) P_{\text {main }}(t) d t \rightarrow \min ; \\
P_{\text {main }}(t)+\sum_{i=1}^{n} P_{i}(t)-P_{\text {load }}(t)=0 .
\end{array}\right.
\end{gathered}
$$

Forecasting information, regarding meteorological parameters, supplied by corresponding subsystem, Smart Grid must be taken into account. This information allows to reproduce rather adequately RSE states of Variable type for the period of up to four. As a result, variable and nonstable sources of energy of WES and SES type in efficiency functions and limitations of optimal control problems can be presented by mathematical expectation of temporal dependences of generation $M_{\mathrm{WES}}\{P(t)\}, M_{\mathrm{SES}}\{P(t)\}, t \in\left[t_{0} ; t_{k}\right]$.

The problem of optimal control (1) can be presented in the following manner. The totality of $n$ controlled RSE (on the example of SHES) and $m$ variable sources - WES and SES are set, mathematic expectation of total active power is

$$
M_{V A R}(t)=M_{W E S}\{P(t)\}+M_{S E S}\{P(t)\} .
$$

Powers of SHES are taken as control variables, since they are the most stable, regarding the influence of the environment. Losses due to transfers of power of variable RSE and SHES in distributive network are functions from generation powers and must be taken into account in efficiency function.

The composition of switched on equipment of SHES during the day and its energy characteristics is stable. It is necessary to find such modes of SHES $P_{i}(t)$ in time interval $\left[t_{0} ; t_{k}\right]$, which would provide maximum profit from selling RSE electric energy at energy market:

Daily discharged at each SHES as well as balance of discharges in the chain $W_{i}=W_{i-1}+d W$ are set as limitations, $d W$ value is determined by stochastic processes of water arrival at the section of the river between $i^{-1} 1^{\text {th }}$ and $i^{\text {th }}$ SHES. Taking into account limitations-inequalities regarding the capacity of controlled RSE $P_{i}^{\min } \leq P_{i}(t) \leq P_{i}^{\max }$ and by pressure $H_{i}^{\min } \leq H_{i}(t) \leq H_{i}^{\max }$ determined by the conditions of operation in water distribution systems is obligatory. Values $P_{i}\left(t_{0}\right)$ and $P_{i}\left(t_{k}\right)$ are considered to be known values. Solution of similar problem is considered in [4]. As the solution, using the principle of maximal integral functions of Pontriagin conditions of RSE optimality functioning are obtained in the form of relations:

$$
\begin{gathered}
z_{\text {main }}^{*}(t)=\frac{\lambda_{1} q_{1}^{*}(t)+q_{1}^{\mathrm{PF}}}{1-\sigma_{1}^{*}(t)}=\frac{\lambda_{2} q_{2}^{*}(t)+q_{2}^{\mathrm{PF}}}{1-\sigma_{2}^{*}(t)}=\ldots=\frac{\lambda_{n} q_{n}^{*}(t)+q_{n}^{\mathrm{PF}}}{1-\sigma_{n}^{*}(t)}(4) \\
\text { where: } z_{\text {main }}^{*}=z_{\text {main }}+z_{\text {main }}^{\prime}, \mathrm{q}_{\mathrm{i}}^{*}=\mathrm{q}_{\mathrm{i}}+\mathrm{q}_{\mathrm{i}}^{\prime} \\
\mathrm{a} \sigma_{\mathrm{i}}^{*}=\sigma_{\mathrm{i}}+\sigma_{\mathrm{i}}^{\prime} \text { on condition that }
\end{gathered}
$$

$$
\left\{\begin{array}{l}
z_{\text {main }}=-\operatorname{tariff}(t) ; \quad z_{\text {main }}^{\prime}=\frac{d \operatorname{tariff}(t)}{d t} \\
q_{i}=\frac{\partial Q_{i}}{\partial P_{i}} ; q_{i}^{\prime}=-\frac{d}{d t} \frac{\partial Q_{i}}{\partial P_{i}} ; q_{i}^{P F}=\frac{\partial P F_{i}^{P}}{\partial P_{i}}+\frac{\partial P F_{i}^{H}}{\partial P_{i}} \\
\sigma_{i}=k_{t} \frac{\partial \Delta D_{R S E}}{\partial P_{i}} ; \quad \sigma_{i}^{\prime}=-k_{t} \frac{d}{d t} \frac{\partial \Delta D_{R S E}}{\partial P_{i}} ;
\end{array}\right.
$$

$Q_{i}$ - water losses for $i^{\text {th }}$ SHES; $\lambda$-Lagrangian multipliers; $\mathrm{PF}_{i}^{P}, \mathrm{PF}_{i}^{\mathrm{H}}$ - penalty functions, introduced to efficiency function for account of limitations, such as, inequalities, by the capacity of $i^{\text {th }}$ RSE and by the pressure between pools, correspondingly (in case, if $i^{\text {th }} \mathrm{RSE}$ is small hydropower station); 
$k_{t}$ - weight coefficient, determined by the ratio of selling tariff for RSE tariff( $(t)$ and the cost of power losses.

Performing optimal control of RSE according to conditions of optimality we provide obtaining maximum profit from selling electric energy from RSE, and we reduce losses in electric networks of LES. It should be noted that the accuracy of mathematical expectation definition of the power of variable sources of energy $M_{V A R}(t)$, influencing only the components of relative increments of losses $\sigma_{i}^{*}$ is not critical for problem solution. From the conditions of optimality (3)-(4) it follows that automatic control system (ACS) of RSE modes in LES must be of active adaptive type. To get system technical - economic effect and maximum profit from RSE their characteristic features must be taken into consideration, as well as the fact that ACS of RSE is the part of ACS of LES, which, in its turn, is the element of optimal control system of electric energy system (EES) of centralized supply. It follows that ACS of RSE by its structure must be hierarchic system. In accordance with the problems, being solved at each hierarchic stage, their information support is formed. Volume of information must be optimal to provide the solution of the problems, dealing with the control of the totality of RSE at different operation conditions and reaching common optimality conditions of RSE, LES and EES. For adaptation of optimal control laws of RSE to the conditions of LES operation communication channels must provide full value information exchange between hierarchic levels of ACS.

\section{AUTOMATION OF RSE MODES OPTIMAL CONTROL IN LOCAL ELECTRIC SYSTEMS}

To realize the above-mentioned problems the necessary condition is to provide the possibility of centralized control over the object in real time. But the above-mentioned condition cannot be completely realized as a result of spatial branching of objects and lack of reliable communication channels between them and dispatching centre. Proceeding from this fact, automatic control system (ACS) with the preset list of functions (Fig. 2) can be built as a centralized system of online control with a decentralized function of real time, as a result of application of local adaptive systems of automatic control (SAC).

Taking into account the structure and material complexity of the given control system, as well as requirements, regarding minimization of capital and operating costs, ACS is built proceeding from the results of detailed technical economic analysis. As a result of such analysis, the concept of automation of RSE stations have been developed. The main principles of such a concept are:

- the sequence of development and implementation of ACS is substantiated, this sequence envisages the priority of problems realization;

- realization of three-level hierarchical structure with allocation of two levels of control of objects which perform the control of the lower level, and "basic" objects. Such a structure reduces capital costs, needed for hardware and software realization of ACS;

- complete independence of the objects of control of all the levels in normal (planned) modes

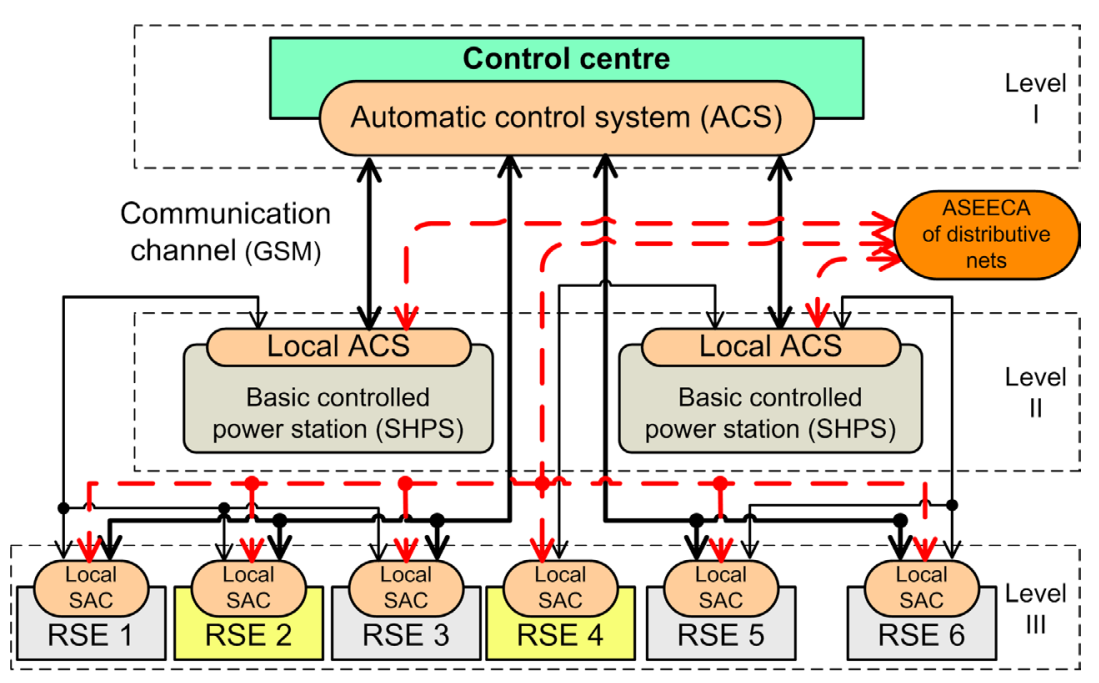

ASEECA - Automatic system of electric energy commercial account

Fig. 2. Structural diagram of ACS RSE 
of their operation allows to provide controllability of the objects and realization of the set functions during certain period of time even in case of failure of communication channels with higher hierarchical level. Development and implementation of ACS by the group of renewable sources energy plants envisages a number of completed stages, each of which is responsible for realization of certain range of problems. At the first stage problems of automation of commercial account of electric energy are solved as necessary condition of RSE functioning at energy market, hardware and software for collection and transfer of data, regarding half-an hour schedules of electric energy supply and formation of reporting documents in accordance with acting standards. Additional tasks to be realized at a given stage are testing of the chosen intelligent meters, hardware platform and communication channels, training of the staff for operation with new equipment.

At the next stage of ACS realization the aim is to automate the process of energy generation and to provide independent operation of RSE in normal (planned) operation modes. Problems of remote switching of renewable sources station, automatic control of operation and protection of main equipment are solved; the solution of these problems will allow to reduce the number of the staff.

The volume of information support considerably increases, because of performing the preset remote operation mode and carry out necessary decisions regarding operation control it is necessary (for a small hydro power station):

- control the level of the water in upper pool and stop the units if minimum level is reached;

- control operation mode of generators, using measuring devices of control panel and correct correspondingly turbines capacity;

- control parameters of mechanical part of hydro power station (bearings of generators, turbines, transmissions) stop the units in case of reaching limiting values of vibration and temperature;

- registration of emergency situations and presence of the staff and strangers on the territory of hydropower station (including video-observation) and information of higher hierarchical level (dispatching centre) and operation staff. Solution of the problems of information support of RSE station mode monitoring requires expansion of hardware-software part of local control systems - installation of sensors (S) of mechanic and electric parameters, as well as actuators (A), connected into information network of the lower level, PLC - controllers for organization of real-time problems performance and data exchange between subsystems of ACS, etc. The third stage of development and realization of ACS RSE starts with allocation (by territorial principle, installed capacity, quality and qualification of the staff) of basic controlled power stations (as a rule - SHPS). At these stations additional equipment for organization of local automatic control system is installed to realize the control over such stations and stations of the lower level, connected with them. PLC-controllers of such objects are incorporated into in local Ethernet network that provides the possibility of data exchange between them and the server of local ACS. The server is equipped with the software that enables to accumulate and analyze retrospective data of the local SAC and SAC of the group of RSE, improve the efficiency of primary energy resources usage, forecast emergency situations and liquidate failures with minimum losses $[9,10]$.

Thus, local ACS of basic power station are intended for independent computer-based control of its operation modes in accordance with the changes of environment parameters, on-line analysis of operation modes of their equipment and transmission of information to dispatching centre and attendant staff of corresponding RSE regarding possible emergencies, analysis of trends of main parameters (electric, mechanic), their registration and organization of information exchange between the objects of control and dispatching centre. It is obvious that realization of the described ACS by RSE requires, besides hardware realization, the development of corresponding mathematic and programming software, which for separate power station (especially for basic power station of the second level) requires capital investments and time. But expenses are reimbursed as a result of better controllability and maneuverability of RSE, reduction of the staff, improvement of operation reliability and efficiency of usage of primary energy potential, as well as fulfillment of the schedule of power generation in LES with such non stable sources of energy as WES and photovoltaic sources. 


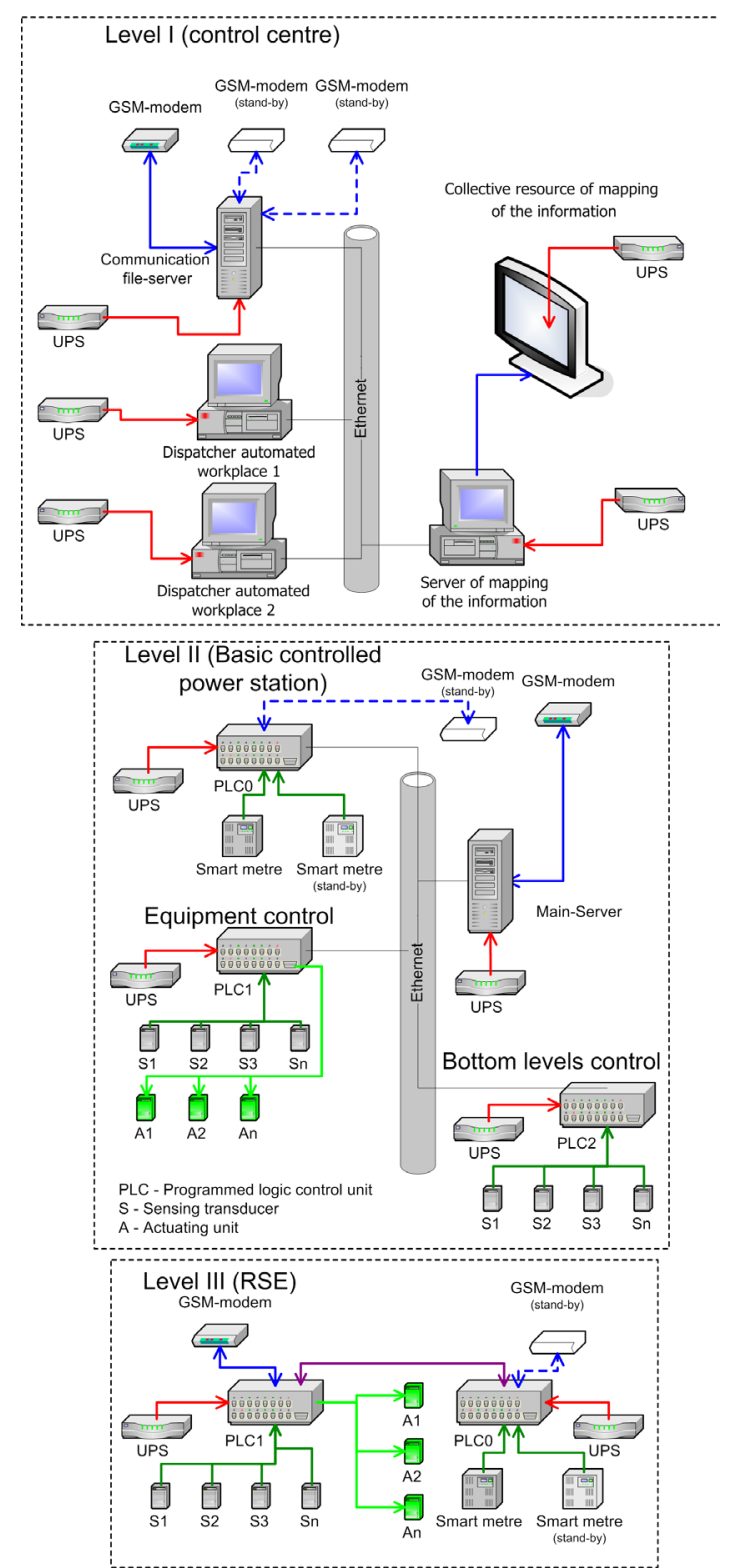

Fig. 3. Structural diagram of hardware realization of ACS RSE

\section{CONCLUSIONS}

1. Possible variants of renewable sources of energy usage in electric system are considered, the conditions of their mutual optimal functioning are substantiated. It is shown that application of Smart Grid technologies enables to solve problems of RSE modes optimization in electric system in a complex manner, on the basis of the suggested optimality conditions.

2. It is expedient to perform optimal control of renewable sources of electric energy using three level control system. In accordance with the problems, solved at each hierarchic level, their information support is formed As a result of flexible feedbacks using communication net- works control of operation modes of separate RSE in order to compensate them to non stable generation is achieved.

3. The suggested structure of optimal control of technological processes of electric energy generation and consumption enables, in conditions of non stability of external impacts to provide reliable and economically expedient operation of RES in various operational situations and meet common optimality conditions of RES, LES and EES.

\section{REFERENCES}

1. Burbelo M., J., Pijarski P., Zavadskiy V., Koczorowska-Gazda A., Lyudmyla M. Melnychuk L. M., Loboda Y. V. Measurement of reactive power under asymmetrical nonsinusoid modes of electric networks with earthed neutral. Proceedings of SPIE, 10031, 2016. doi: 10.1117/12.2248788.

2. European Smart Grids Technology Platform // European Commission. Directorate-General for Research Sustainable Energy System, EUR 22040, 2006, 4.

3. Kacejko P., Machowski J., Pijarski P.: Standing phase angle reduction at switching operation in transmission network. Rynek Energii. 5(96), 2011, 24-35.

4. Kacejko P., Pijarski P. Connecting of wind farms limitations instead of oversized investment. Rynek Energi.1(80), 2009,10-15.

5. Kacejko P., Pijarski P. Cost sharing on the network upgrade individual investors applying for connection to a network of wind farms . Przegląd Elektrotechniczny 9a (88), 2012, 27-31.

6. Kacejko P., Pijarski P.: Dynamic Fitting of Generation Level to Thermal Capacity of Overhead Lines. Przegląd Elektrotechniczny, 84(5), 2008, 80-83.

7. Lezhniuk P.D., Kulyk V.V., Burykin O.B. Kovalchuk O.A. Optimization of electric grids modes with small hydropower stations in conditions of addressing energy supply // Technical electrodynamics. Thematic issue: Problems of Modern Electric Engineering. 3. 2010, 31-34.

8. Montusiewicz J., Gryniewicz_Jaworska M., Pijarski P.Looking for the optimal location for wind farms. Advances in Science and Technology Research Journal. 27(9), 2015, 135-142.

9. NIST Releases Report on Smart Grid Development // National Institute of Standards and Technology (USA) - Recognized Standards for Inclusion In the Smart Grid Interoperability Standards Framework, Release 1.0 (Electronic resource). Access mode: http://collaborate.nist.gov/twiki- sggrid/bin/view/_ SmartGridInterimRoadmap/InterimRoadmapFinal

10. Stogniy B.S., Kyrylenko O.V., Denysiuk S.P. Inteligent elecric gridsof electric systems and their information support. Technical Electrodynamics. 6, 2010, 44-50. 